\title{
A Familial Syndrome With Coats' Reaction Retinal Angiomas, Hair and Nail Defects and Intracranial Calcification
}

\author{
J. L. TOLMIE*, B. H. BROWNE+, P. M. McGETTRICK† and J. B P. STEPHENSON \\ Glasgow
}

\begin{abstract}
Summary
We describe two sisters who have bilateral Coats reaction of the retina, intracranial calcification, sparse hair and dysplastic nails. The younger sibling has in addition distinct retinal angiomas in one eye. This combination of clinical findings has not been reported previously and is probably due to an autosomal recessive gene defect. Laser photocoagulation and cryotherapy has preserved good function in one eye of each child.
\end{abstract}

Coats' disease ${ }^{1}$ comprises exudative retinal detachment associated with congenital retinal telangiectasia. The clinical and pathological criteria for its diagnosis were reemphasised by Manschot and de Bruijn.2 Most cases are unilateral. non-inherited and occur predominantly in males with average age of onset at 10 years..$^{3 .+}$ Recently we reported the results of angiographic, light and electron microscopic studies of one eye of a three year old girl with bilateral asymmetrical Coats' disease. ${ }^{5}$ Although the early age of onset, female sex and bilaterality were atypical, the ocular pathological features were entirely consistent with this diagnosis.

Since our original report it has become evident that both this patient and her young sister have bilateral Coats' disease in association with abnormalities of the brain, hair and nails. Further, the less seriously affected left eye of the younger sister also demonstrates distinct angioma formation in the mid periphery though without the enlarged feeder vessels present in von Hippel-Lindau disease. We therefore describe further clinical details of these siblings who, most likely, have a hitherto unreported syndrome with autosomal recessve inheritance.

\section{Clinical Reports}

The affected sisters (Fig 1) were the first surviving children of non-consanguinous Scottish parents who are in good health and without any family history of ocular disease. The mother's first pregnancy ended with the birth of twin daughters at 34 weeks gestation who died at age 1 day and 4 days respectively from hyaline membrane disease. Post-mortem examinations were performed on both infants and the only abnormality noted apart from the complications of their prematurity, was absence of the left kidney in the secondborn twin.

\section{Case 1}

The older affected child was born at 38 weeks gestation by elective caesarian section for intrauterine growth retardation. Birth weight was $2.2 \mathrm{~kg}$ (3rd percentile) and no abnormalities were noted. Oxygen therapy was not required. Early growth and development were normal. At age 3 years her mother noted strabismus and a white pupillary reflex in the left eye. Subsequent ophthalmologi-

From: *The Duncan Guthrie Institute of Medical Genetics and †Fraser of Allander Assessment Unit (Paediatric Neurology) The Royal Hospital for Sick Children, Glasgow and + The Tennent Institute of Ophthalmology, The Western Infirmary, Glasgow.

Correspondence to: Dr B H Browne, The Tennent Institute of Ophthalmology, The Western Infirmary, Glasgow G11 6NT 


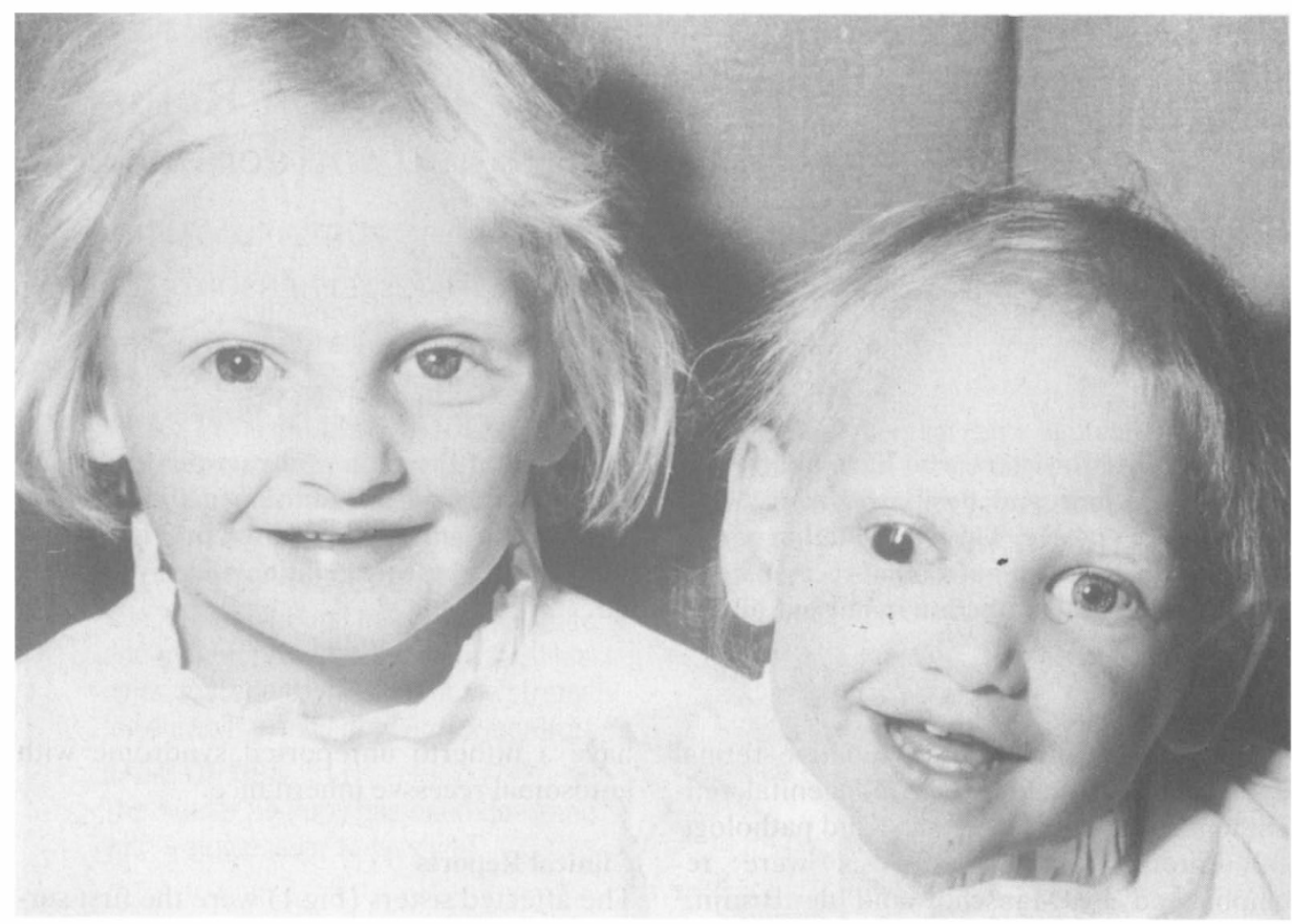

Fig. 1. The sisters reported at ages 5 years 4 months and 3 years 2 months. Note the sparse, wispy hair. The elder sister (case 1) wears a left ocular prosthesis. The younger sister (case 2) has a divergent right eye with a fixed dilated pupil.

cal investigations resulted in the diagnosis of bilateral Coats' disease. The left eye showed advanced disease with severe secondary glaucoma and was enucleated. Abnormal vessels in the right eye were treated with argon laser using the theatre operating microscope. The ocular abnormalities, which we described in detail previously, ${ }^{5}$ comprised an exudative vasculopathy of the retina with ultrastructural evidence of inter-endothelial cell separation and formation of retinal capillary endothelial fenestrations.

Re-assessment of the proband was undertaken after her younger sister presented to the paediatric neurology service with seizures. At age 4 years she was a slightly built child whose height and head circumference (OFC) were on the 25 th percentile. Additional findings were sparse hair, relative midface hypoplasia, a dysplastic left index finger nail and slight cutaneous webbing between the second and third digits (Fig 1 and 2). Sweating was normal when stimulated by warmth. The primary dentition appeared normal. A skull X-ray was normal but a cranial CT scan showed calcification in the region of the putamen extending anteriorly into the internal capsule (Fig 3).
Serum calcium, phosphate, alkaline phosphatase, and immunoglobulins were all normal as was a blood count and film. Urinary tubular resorption of phosphate, phosphate excretion index and the calcium: creatinine ratio was also normal. Chromosome analysis revealed an apparently normal female karytype, $46, \mathrm{XX}$. Hair microscopy revealed hypopigmentation with slight weathering but the changes were not considered characteristic of conditions which go with fragility of hair or sulphur deficiency. Detailed psychological testing revealed a competent child with a full scale IQ of 100 (Stanford-Binet). Her right eye has an acuity of 6/6 (Sheriden-Gardiner) and intraocular pressure was $12 \mathrm{~mm} \mathrm{Hg}$. The retina was flat with total regression of telangectasia following photocoagulation.

\section{Case 2}

The probands sister was also born by elective caesarian section at 35 weeks gestation for intrauterine growth retardation. Birth weight was $2.1 \mathrm{~kg}$ (10th percentile) and no abnormalities were noted. Oxygen therapy was not required. At age 7 months she had a generalised seizure associated 


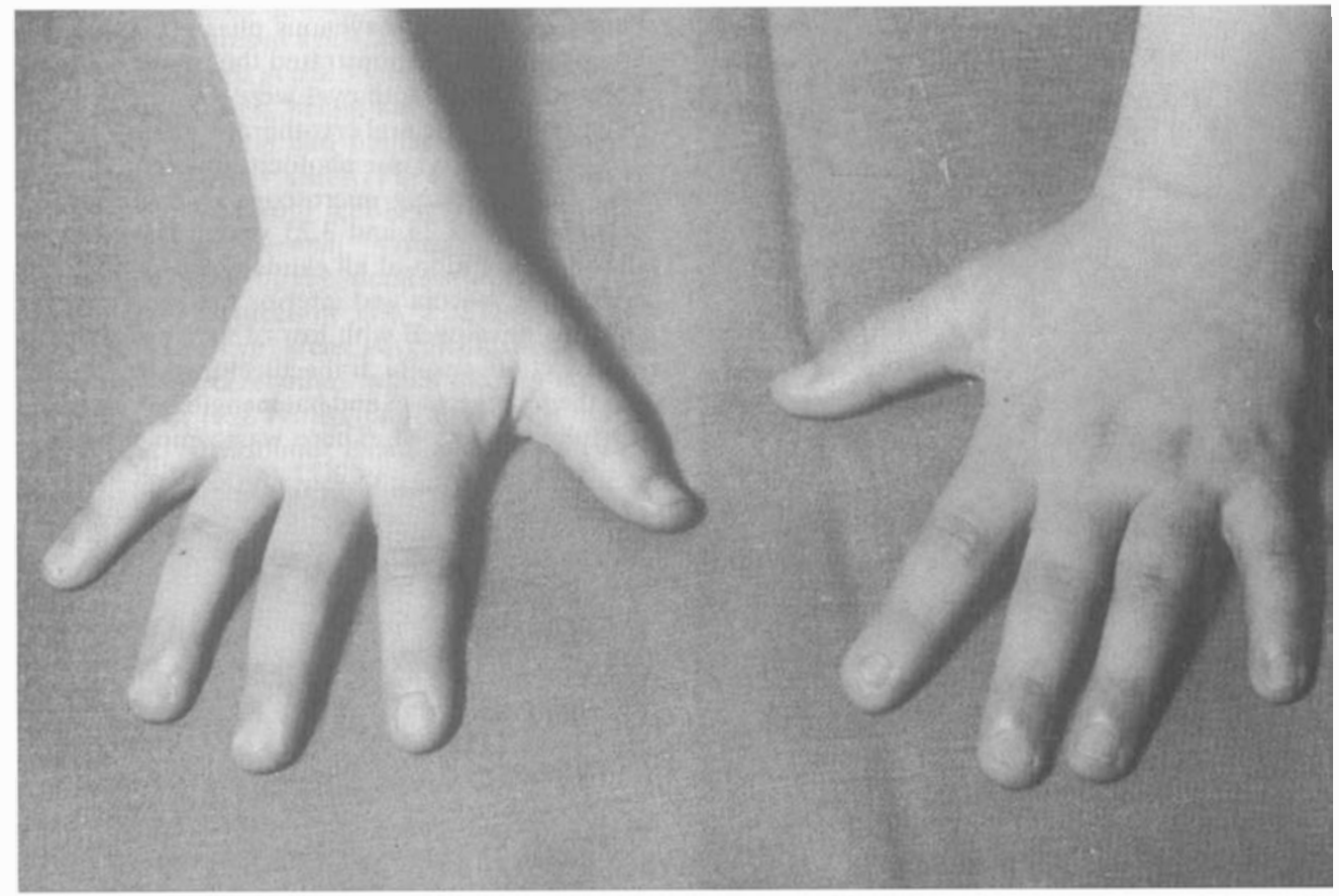

Fig. 2. Case 1: dysplastic left index fingernail.

with fever: a further seizure at age 1 year was followed by a transient left hemiparesis, an EEG was normal as was her development at that age. At age

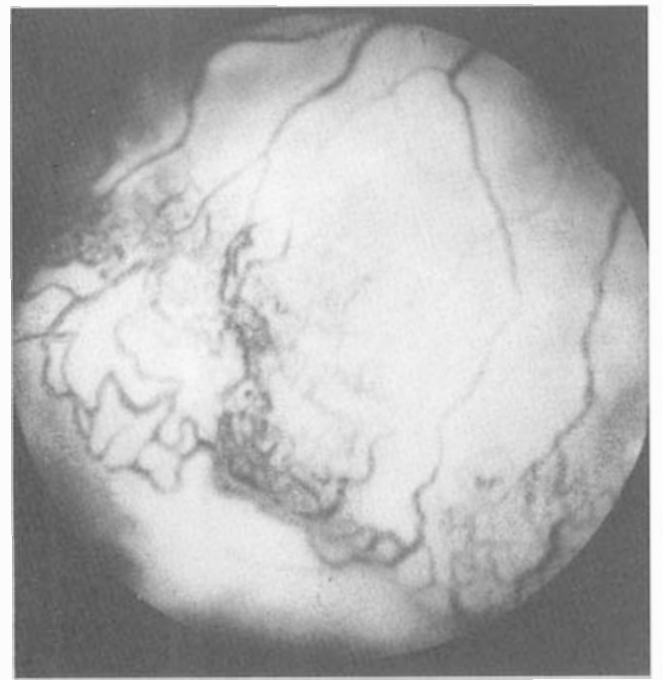

Fig. 4. Case 2: right eye, inferotemporal retinal telangiectasia, subretinal exudate and peripheral avascular zone.

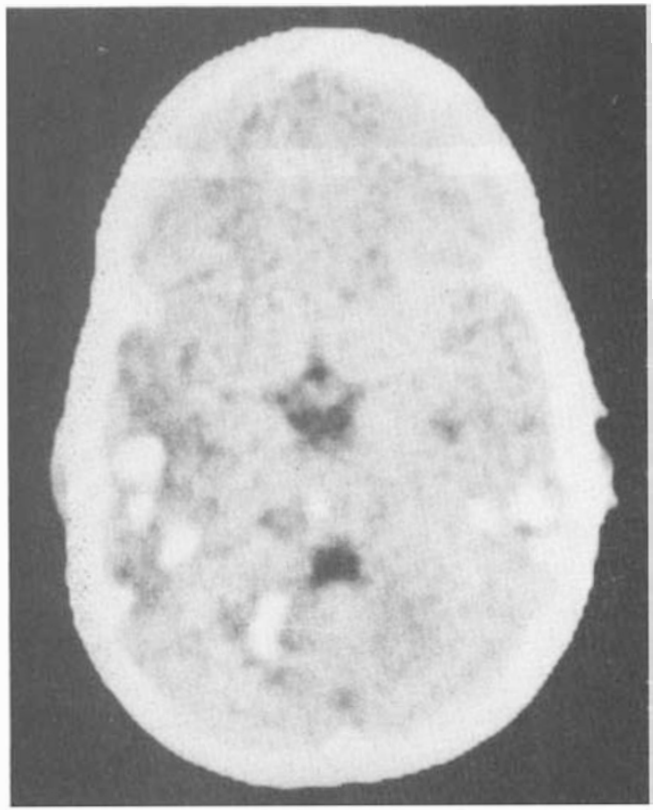

Fig. 3. Case 1: CT scan demonstrating calcification which was present in the cerebrum, cerebellum and basal ganglia. 
2 years 2 months she presented with a right divergent strabismus and on examination under anaesthesia was found to have bilateral retinal abnormalities and exudates similar to those of her sister. The more seriously affected right eye showed extensive retinal telangectasia a peripheral zone of avascular retina and a total retinal detachment with creamy yellow subretinal exudates (Fig 4). The left eye showed retinal telangectasia with a peripheral avascular zone and a limited exudative detachment with a macular star (Fig 5a). In addition, in the left temporal and infero-temporal mid periphery there were five distinct angiomas (Fig $5 b)$ which on fluorescein angiography filled in the early arterial phase (Fig 6a) and fluoresced bril-
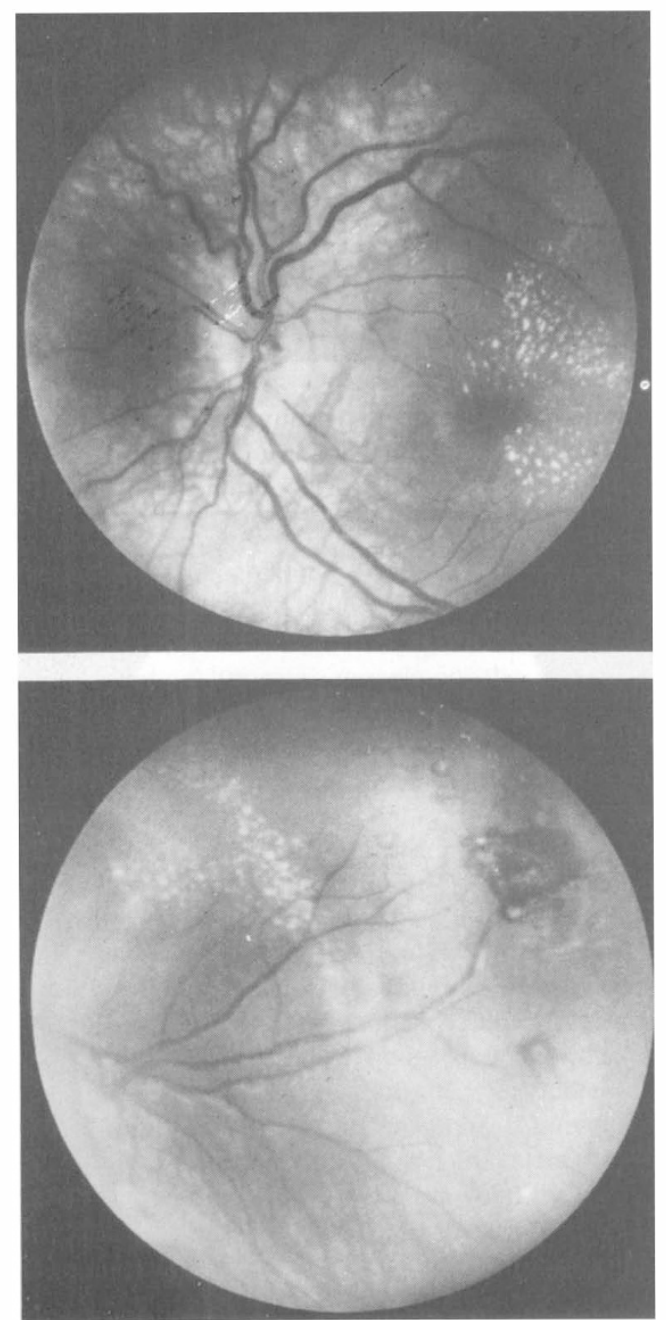

Fig. 5. Case 2: left eye (A) macular star, (B) Infero temporal arcade with a group of distinct angiomas in the retinal vasculature. liantly in the arteriouvenous phase (Fig 6b). The angiogram also demonstrated the totally avascular peripheral zone. Both eyes were treated by a combination of transcleral cryotherapy and transpupillary argon green laser photocoagulation delivered using the operating microscope over six sessions between ages 2.25 and 3.25 years. The right eye showed resolution of all exudate except a shallow area in the macula and inferior fundus. However, rubeosis developed with loss of demonstrable visual function despite trabeculectomy. In the left eye the telangectasia and haemangiomas were successfully obliterated. There was complete resolu-
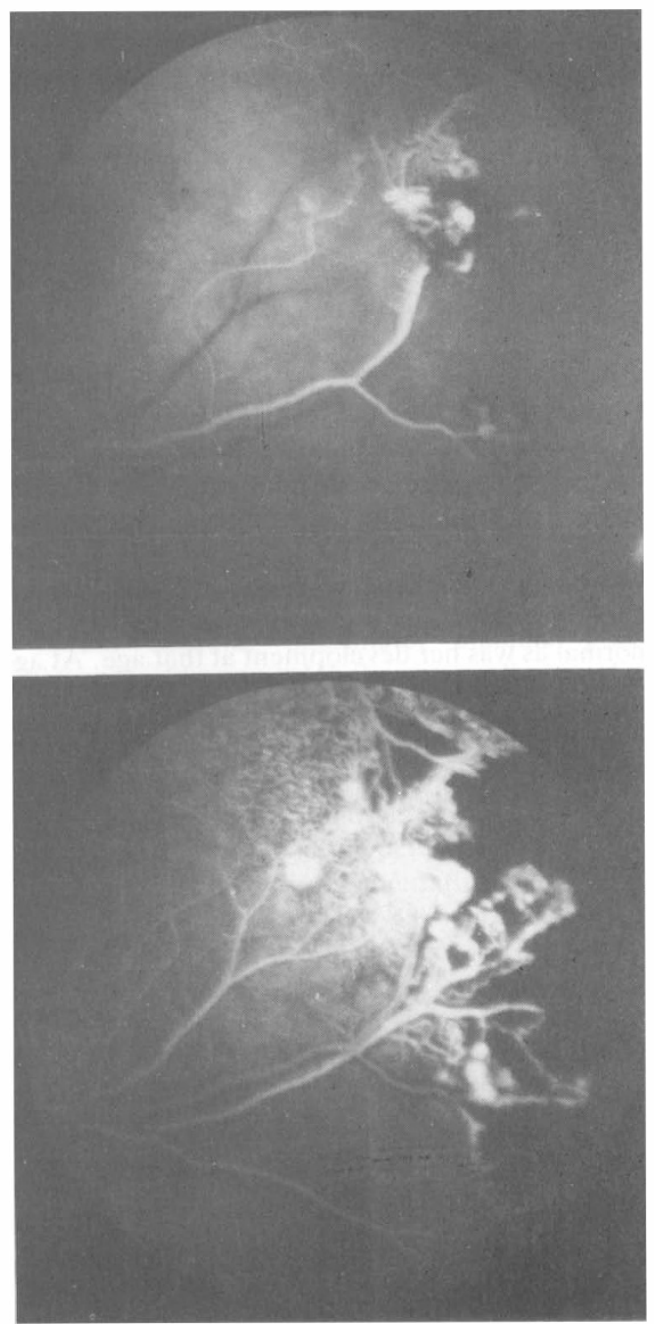

Fig. 6. Case 2: left eye. Fluorescein angiogram in (A) early arterial phase and (B) arteriovenous phase showing early filling and late hyperfluorescence of angiomas seen in fig. 5. Note the totally avascular peripheral zone. 
tion of the exudate and the acuity was recorded as $6 / 9$ by Kay pictures at age 3.25 years.

When examined at age 3 years development was appropriate for age, height and OFC were on the 25th percentile, she had similar sparse, hypopigmented hair to her sister (Fig 1) and dysplastic, deep set nails on both feet (Fig 8). Her primary dentition was normal. Other investigations included a skull X-ray demonstrating feathery intracranial calcification and a CT scan which revealed extensive areas of calcification in the cerebrum and cerebellum which did not enhance with contrast (Fig 7). Skeletal survey was normal and renal ultrasound examinations failed to demonstrate the presence of a left kidney. Estimations of plasma calcium, phosphate, alkaline phosphatase, immunoglobulins and full blood count gave normal results. Chromosome analysis revealed a normal female karyotype, $46, \mathrm{XX}$.

At age 3.5 years a cerebellar ataxia with intention tremour affecting the left arm became evident.

Ophthalmological examination of both parents revealed no abnormalities. it was noted that both had an OFC near the 75th percentile whereas their affected daughters OFCs were on the 25 th percentile.

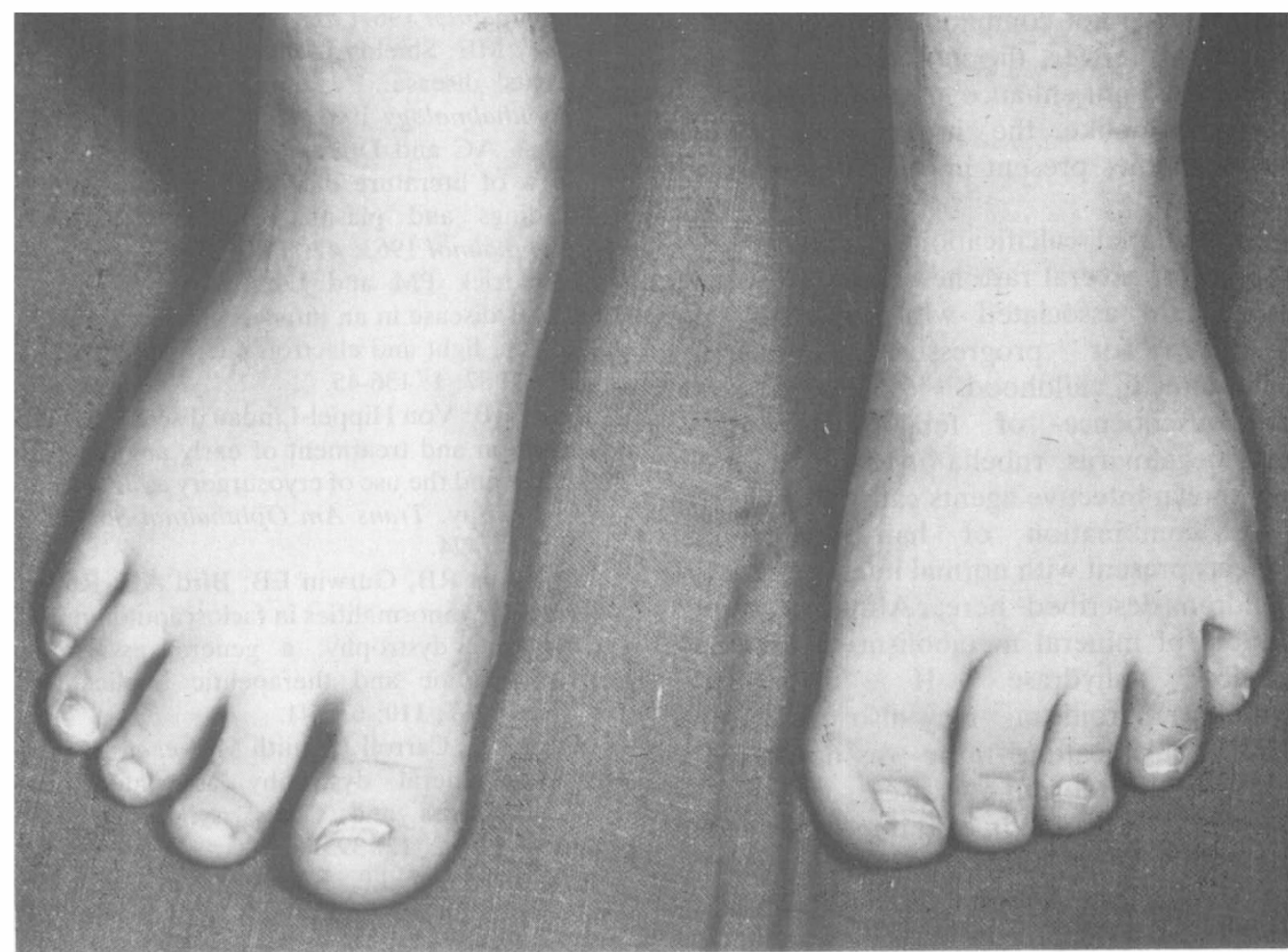

Fig. 8. Case 2: deep set dysplastic toenails.

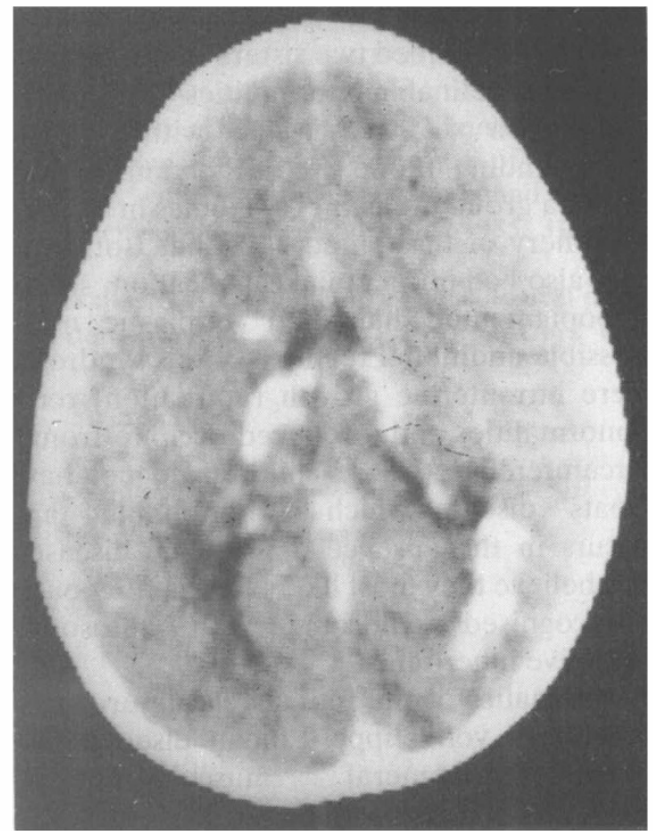

Fig. 7. Case 2: CT scan demonstrating calcification which was present in the cerebrum and cerebellum. 


\section{Discussion}

We have described two sisters who each have bilateral retinal abnormalities fitting the description of Coats' disease, with the additional finding in one eye of the younger sibling of a group of distinct angiomas in the mid periphery of the temporal retina. Both siblings also had intracranial calcification, sparse hypopigmented hair and dysplastic nails. Possible additional features of this syndrome were intrauterine growth retardation, renal abnormalities and a reduced occipito-frontal circumference. These children do not have Coats' disease which is non-familial and occurs in the absence of systemic disease. ${ }^{2}$ We believe they most likely have a previously unrecognised syndrome with autosomal recessive inheritance.

Anomalies of the retinal vasculature are a feature of von Hippel-Lindau disease ${ }^{6}$ and fascioscapulohumeral muscular dystrophy. ${ }^{7,8,9}$ Retinal telangiectasia has also been reported with hypogammaglobulinaemia. ${ }^{10}$ However, the distinctive clinical and radiological findings present in our patients are not compatible with these diagnoses. Moreover, the intracerebral calcified lesions did not enhance after the injection of contrast unlike the intracranial vascular abnormalities present in von Hippel-Lindau disease.

Intracranial calcification in children is a feature of several rare hereditary conditions which are associated with severe mental handicap or progressive neurological symptoms in childhood. ${ }^{11,12,13}$ It may also be a consequence of fetal infection by cytomegalovirus, rubella or toxoplasma, but no known infective agents cause the remarkable combination of hair-brain-eye-nail defects present with normal intellect as in the children described here. Although disturbances of mineral metabolism such as carbonic anhydrase II deficiency, ${ }^{14}$ hypoparathyroidism ${ }^{15}$ may also cause intracranial calcification, there was no evidence for these disorders in our cases.

In the light of our experience we would recommend that although Coats' disease in its classical form is most commonly non-familial, the first degree relatives of each case should also be examined especially if there are symptoms of extra-ocular disease. We also re-emphasise the treatable nature of exudative retinal detachment secondary to congenital retinal telangectasia when diagnosed at an early stage. A laser delivery system permitting transpupillary photocoagulation with the operating microscope under general anaesthesia is of particular value in this context.

We thank Dr R P Barclay and Professor W S Foulds for permission to report this family, Dr E I McNaught for making the initial referral, Dr Rodney Dawber for examining their hair, the Department of Radiology, The Royal Hospital for Sick Children, Glasgow for performing and reporting the radiographic studies and Mrs A Currie for photographic work.

\section{References}

${ }^{1}$ Coats G: Forms of retinal disease with massive exudation. $R$ Lond Ophthal Hosp Rep 1808: 17: $440-525$.

2 Manschot WA and de Bruijn WC: Coats' disease: definition, and pathogenesis. $\mathrm{Br} J$ Ophthalmol 1967; 51: 145-57.

${ }^{3}$ Ridley ME, Shields J, Brown GC, Tasman W: Coats' disease. Evaluation of management. Ophthalmology 1982; 89: 12. 1381-7.

${ }^{4}$ Woods AC and Duke JR: Coats' disease: review of literature diagnostic criteria, clinical findings and plasma lipid studies. $B r \quad J$ Ophthalmol 1963: 47: 385-410.

${ }^{5}$ McGettrick PM and Loeffler KU: Bilateral Coats disease in an infant (A clinical, angiographic, light and electron microscopic study). Eye 1987; 1: 136-45.

${ }^{6}$ Welch RB: Von Hippel-Lindau disease: the recognition and treatment of early angiomatosis retina and the use of cryosurgery as an adjunct to therapy. Trans Am Ophthalmol Soc 1970; 68: $367-424$.

${ }^{7}$ Fitzsimons RB, Gurwin EB, Bird AC: Retinal vascular abnormalities in facioscapulohumeral muscular dystrophy: a general association with genetic and therapeutic implications. Brain 1987; 110: 638-41.

${ }^{8}$ Taylor DA, Carroll J, Smith ME, et al.: Facioscapulohumeral dystrophy associated with hearing loss and Coats' syndrome. Ann Neurol 1982; 12: 395-8.

${ }^{9}$ Wulff JD, Lin JT, Kepes JJ: Inflammatory facioscapulohumeral muscular dystrophy and Coats syndrome. Ann Neurol 1982; 12: 398401. 
${ }^{10}$ Frankel M and Russe HP: Retinal telangiectasia associated with hypogammaglobinaemia. Am J Ophthalmol 1967; 63: 215-20.

${ }^{11}$ Bundey S: Genetics and neurology. Edinburgh: Churchill Livingstone 1985; 302-3.

${ }^{12}$ Burn J, Wickramasinge HT, Harding B, Baraitser M: A syndrome with intracranial calcification and microcephaly in two sibs resembling intrauterine infection. Clin Genet 1986; 30: 112-16.

${ }^{13}$ Baraitser M, Brett EM, Piesowicz AT: Mic- rocephaly and intracranial calcification in two brothers. J Med Genet 1983; 29: 210-12.

${ }^{14}$ Sly W, Whyte MP, Sundaram V, et al .: Carbonic anhydrase II deficiency in 12 families with the autosomal recessive syndrome of osteopetrosis with renal tubular acidosis and cerebral calcification. New Engl J Med 1985; 313: 13945.

${ }^{15}$ Baraitser M: The genetics of neurological disorders. Revised edition. Oxford: Oxford University Press. $1985 ; 245-8$. 